(c) American Dairy Science Association, 2005.

\title{
Size Distribution of Fat Globules in Human Colostrum, Breast Milk, and Infant Formula
}

\author{
M. C. Michalski, ${ }^{1}$ V. Briard,${ }^{1}$ F. Michel, ${ }^{1}$ F. Tasson, ${ }^{2}$ and P. Poulain ${ }^{2}$ \\ ${ }^{1}$ INRA-UMR 1253, Science et Technologie du Lait et de l'Oeuf Agrocampus 65, rue de Saint-Brieuc, \\ 35042 Rennes Cedex, France \\ ${ }^{2}$ Maternité de l'Hôtel Dieu, CHU de Rennes-2, rue de l'Hôtel Dieu, 35000 Rennes, France
}

\section{ABSTRACT}

Only a few results are available on the size of human milk fat globules (MFG), despite its significance regarding fat digestion in the infant, and no data are available at $<24 \mathrm{~h}$ postpartum (PP). We measured the MFG size distribution in colostrum and transitional human milk in comparison with fat globules of mature milk and infant formula. Colostrum and transitional milk samples from 18 mothers were collected regularly during $4 \mathrm{~d} \mathrm{PP}$ and compared with mature milk samples of 17 different mothers and 4 infant formulas. The size distribution was measured by laser light scattering. For further characterization, the $\zeta$-potential of some mature MFG was measured by laser Doppler electrophoresis. The MFG diameter decreased sigmoidally in the first days. At $<12 \mathrm{~h} \mathrm{PP}$, the mode diameter was $8.9 \pm 1.0 \mu \mathrm{m}$ vs $2.8 \pm 0.3 \mu \mathrm{m}$ at $96 \mathrm{~h} \mathrm{PP}$. Thus, the surface area of MFG increased from $1.1 \pm 0.3$ to $5.4 \pm$ $0.7 \mathrm{~m}^{2} / \mathrm{g}$ between colostrum and transitional milk. In mature milk, the MFG diameter was $4 \mu \mathrm{m}$ on average and increased with advancing lactation, whereas the droplets in infant formula measured $0.4 \mu \mathrm{m}$. The $\zeta$ potential of mature MFG was $-7.8 \pm 0.1 \mathrm{mV}$. The fat globules are larger in early colostrum than in transitional and mature human milk and in contrast with the small-sized fat droplets in infant formula. Human MFG also have a low negative surface charge compared with bovine globules. These structural differences can be of nutritional significance for the infant. (Key words: human milk, milk fat globule, size distribution, $\zeta$-potential)

Abbreviation key: $\mathbf{d}_{\mathbf{3 2}}=$ volume-surface average diameter, $\mathbf{d}_{43}=$ volumic average diameter, $\mathbf{M F G}=$ milk fat globule, $\mathbf{P P}$ = postpartum, $\mathbf{S S A}=$ specific surface area.

Received January 13, 2005.

Accepted February 23, 2005

Corresponding author: M. C. Michalski; e-mail: marie-caroline. michalski@rennes.inra.fr.

\section{INTRODUCTION}

Fat is a major component of human milk and is composed of $>98 \%$ triacylglycerols (Mulder and Walstra, 1974; Hamosh et al., 1985; Jensen et al., 1990). The nonpolar nature of milk lipids prevents solubility in the aqueous phase, within the mammary secretory cells before secretion, as well as in milk (Hamosh et al., 1999). Thus, fat globules are formed throughout the mammary epithelial cell, grow in size as they move toward the apical cell membrane, and are extruded into the alveolar lumen (Jensen et al., 1990; Keenan and Dylewski, 1995; Keenan, 2001; Ollivier-Bousquet, 2002). During the extrusion process, the globule is enveloped by portions of the cell membrane, which becomes the milk fat globule (MFG) membrane. The core of the MFG contains triacylglycerols (Figure 1), and the membrane has the general composition of biological membranes, i.e., phospholipid, cholesterol, glycoproteins, enzymes, etc. (Anderson and Cawston, 1975; McPherson and Kitchen, 1983; Christie, 1995; Keenan and Dylewski, 1995; Hamosh et al., 1999). The physico-chemical properties [structure, size distribution, electrokinetic potential (or so-called $\zeta$-potential), and thermal behavior] of bovine MFG have been widely studied (Walstra, 1969; Mulder and Walstra, 1974; Christie, 1995; Walstra, 1995; Lopez et al., 2000; Michalski et al., 2002d; Briard et al., 2003).

Many studies concern the chemical nature and biochemical significance of human milk lipids (Emmett and Rogers, 1997; Francois et al., 1998; Villalpando and del Prado, 1999; Fidler and Koletzko, 2000; Francois et al., 2003; Schweigert et al., 2004). However, despite the great significance of the physical structure of milk fat regarding lipase acitivity, cholesterol availability and lipid absorption in the gastrointestinal tract of neonates (Bitman et al., 1983; Armand et al., 1996; Armand, 1998; Armand et al., 1999; Hamosh et al., 1999; Lönnerdal, 2003), only a few researchers have studied the size distribution of human MFG (Whittlestone and Perrin, 1954; Rüegg and Blanc, 1981, 1982; Simonin et al., 1984). Since the latter studies, in which a microscope or a particle counter were 


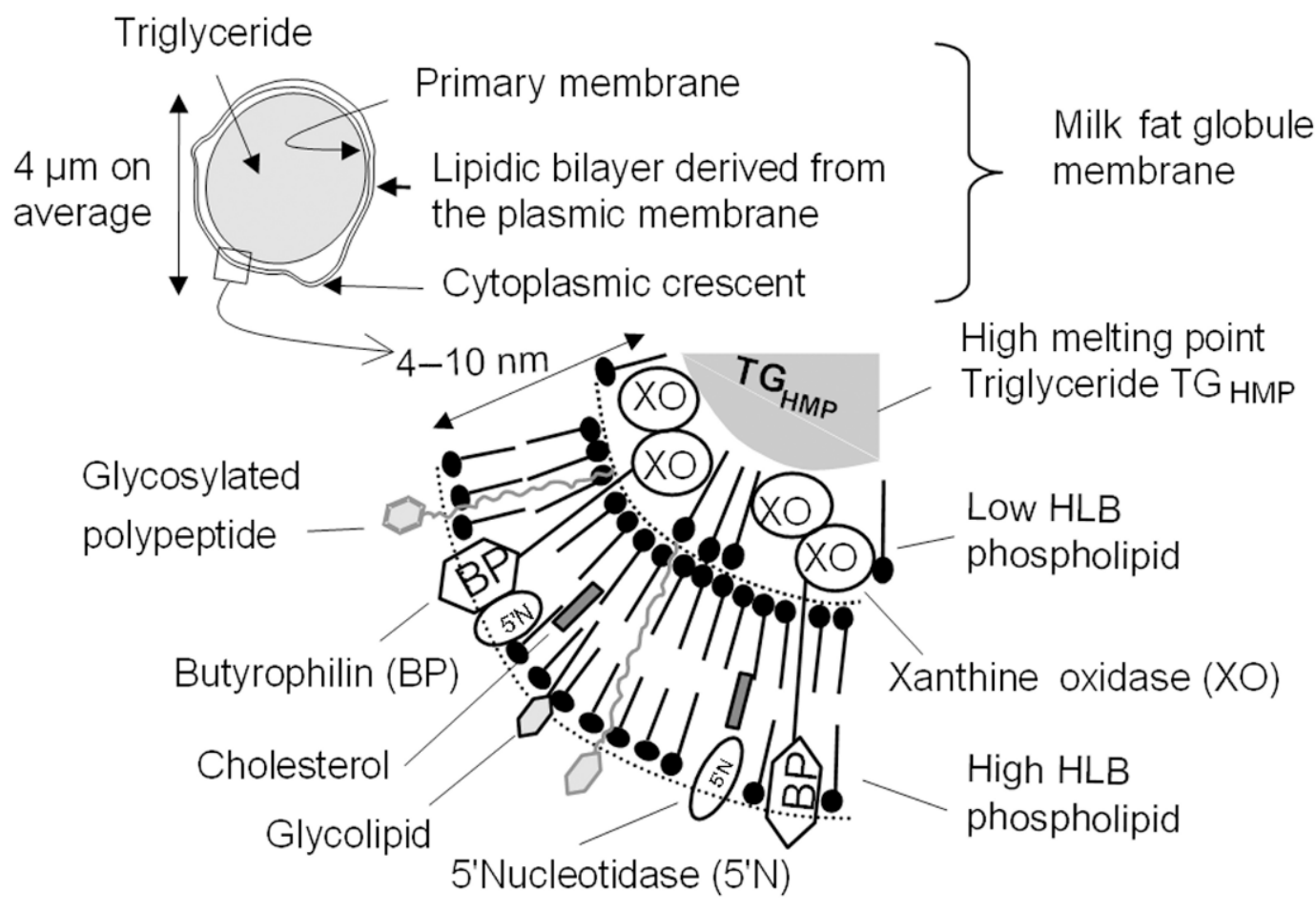

Figure 1. Typical structure of the native milk fat globule. Schemes are not to scale.

used, laser light scattering devices have been developed (McCrae and Lepoetre, 1996); the newest ones allow a better study of MFG size distribution from submicronic to micrometric particles thanks to 2 different laser beams (Michalski et al., 2001). To our knowledge, no MFG size data are available to date regarding colostrum during the first $24 \mathrm{~h}$ after delivery, although it is known that colostrum composition varies greatly within the first $4 \mathrm{~d}$ postpartum (PP) (Jensen et al., 1990). Also, the surface properties of human MFG, such as their electrokinetic- or $\zeta$-potential, which accounts for the surface charge of the globules and can affect globule interactions with proteins and lipases, have not been yet characterized.

The aim of the present study was to measure the fat globule size distribution in colostrum and transitional milk from mothers having delivered term infants during the first $4 \mathrm{~d}$ of lactation and to compare it with fat globule size measured from 1) mature human milk samples from other mothers corresponding to 1 to 37 mo of lactation and 2) infant formula for term infants. Typical physico-chemical parameters of the fat globules were characterized (average diameters, specific surface area, and span and $\zeta$-potential and fat content for the mature milk of one mother) and compared with literature results regarding human, cow, and homogenized cow milk.

\section{MATERIALS AND METHODS}

\section{Breast Milk Samples}

Colostrum and breast milk samples from 18 volunteer mothers, who had delivered at term and signed an informed agreement for participating in the study, were collected twice a day [once in the morning and once in the evening from delivery (colostrum) to the end of the 4-d stay in the hospital (transitional milk)]. Consistent characteristics of the volunteer mothers are shown in Table 1 . Thirteen mothers (71\%) delivered with epidural analgesia; one of them delivered by caesarean. All samples were collected with midwife supervision by manual expression in microtubes without preservative. For ethical reasons, samples were collected from the sucked breast at the end of nursing so that the fat milk could be analyzed (Aksit et al., 2002). This method is physiologically consistent as the milk obtained by manual or mechanical expression may not have the same composition as milk consumed during breastfeeding itself (Lucas et al., 1977; Aksit et al., 2002). Some samples were also collected from the opposite breast before nursing to check that fat globule size did not vary throughout the single feeding. The samples were stored at $4^{\circ} \mathrm{C}$ until they were analyzed in the laboratory the day after collection. Preliminary experiments in our laboratory had shown that 
Table 1. Characteristics of the volunteer mothers $(n=18)$ whose colostrum and milk were analyzed during the first $4 \mathrm{~d}$ postpartum. Means are expressed \pm SEM.

\begin{tabular}{lllr}
\hline & Minimum & Maximum & Mean \\
\hline Age, yr & 24 & 41 & $30.9 \pm 1.0$ \\
Weight at parturition, kg & 58 & 84 & $70.8 \pm 2.3$ \\
Weight gain during pregnancy, $\mathrm{kg}$ & 8.5 & 24 & $11.7 \pm 1.0$ \\
Child rank & 1 & 5 & $1.9 \pm 0.3$ \\
Total previous nursing duration, mo & 0 & 22 & $3.5 \pm 1.5$ \\
Term, wk & 37 & 41 & $40.0 \pm 0.3$ \\
\hline
\end{tabular}

overnight storage at $4^{\circ} \mathrm{C}$ did not affect the fat globule size. The study was in accordance with the rules of the ethics committee of the hospital. All women were fed the same hospital diet. The main sources of dietary fat were vegetable oil, cheese, yogurt, meat, and fish.

As a complementary study, we collected the mature milk of 17 other volunteer mothers whose stage of lactation was different, between 1.5 and $37 \mathrm{mo}$.

In addition to breast milk samples, 4 commercial infant milk formulas were studied [Gallia $1^{\mathrm{er}}$ âge, Danone, Paris, France; Guigoz Evolier $1^{\text {er }}$ âge, Guigoz $2^{\mathrm{e}}$ âge, Nestlé, Paris, France; Novalac $2^{\mathrm{e}}$ âge, Novalac, Paris, France) after dispersion in water at $37^{\circ} \mathrm{C}$ at 14 to $16 \%$ according to the manufacturer's instructions. Fat droplets in these formulas were made of emulsified vegetable oils (no lactic fat).

\section{Particle Size and $\zeta$-Potential Measurements}

The apparatus and method for particle size analysis have been described in detail by Michalski et al. (2001). The fat globule size distribution was measured by laser light scattering using a Mastersizer2000 (Malvern, UK) with 2 laser sources, allowing the characterization of micronic as well as submicronic populations. To prevent artefacts regarding submicronic globules, the casein micelles (usually $\sim 150 \mathrm{~nm}$ ) were dissociated by diluting the sample in $35 \mathrm{~m} M$ EDTA ( $\mathrm{pH}$ 7) prior to measurement. Dispersion in $0.1 \%$ SDS allowed dissociation of clusters in homogenized infant formulas (Michalski et al., 2001). For the software to calculate particle size distributions from the measured laser light scattering patterns, it is necessary to know the refractive index of the particles. In preliminary experiments, we found that the same refractive index, such as that of cow milk fat, could be used for breast MFG of women fed a Western diet rich in dairy products (i.e., 1.458 and 1.460 for milk fat at 633 and $466 \mathrm{~nm}$, respectively). Refractive index increased by only 0.002 for women fed a diet without dairy products and rich in fish and vegetable oils, which was not found to affect size distributions significantly. Because infant formulas contain a mixture of palm, sunflower, coconut, and rapeseed oils, their mean refractive index of 1.462 was used.
Standard parameters were calculated by the software: the mode diameter (diameter at the peak maximum); the volumic average diameter $\left[\mathbf{d}_{\mathbf{4 3}}=\Sigma\left(\mathrm{v}_{\mathrm{i}} \times \mathrm{d}_{\mathrm{i}}\right) /\right.$ $\Sigma \mathrm{v}_{\mathrm{i}}$ (where $\mathrm{v}_{\mathrm{i}}$ is the volume of globules in a size class of average diameter $\left.d_{i}\right)$ ]; the volume-surface average diameter $\left.\left[\mathbf{d}_{32}=\Sigma \mathrm{v}_{\mathrm{i}} / \Sigma \mathrm{v}_{\mathrm{i}} / \mathrm{d}_{\mathrm{i}}\right)\right]$; the specific surface area (SSA $=6 \times \rho^{-1} \times \mathrm{d}_{32}{ }^{-1}$, where $\rho$ is the milk fat density); and the distribution $\left[\mathrm{span}=\left(\mathrm{d}_{0.9}-\mathrm{d}_{0.1}\right) / \mathrm{d}_{0.5}\right.$, where $\mathrm{d}_{0.9}$ is the diameter below which lie $90 \%$ of the globule volume and, respectively, $10 \%$ for $\mathrm{d}_{0.1}$ and $50 \%$ for $\mathrm{d}_{0.5}$ ]. The mean free distance between fat globules $\left(\mathrm{d}_{\text {free }}\right)$ was calculated from our results and from the literature as $\mathrm{d}_{\text {free }}=0.225 \times \mathrm{d}_{32} \times[(0.74 / \mathrm{F})-1]$, where $\mathrm{F}$ is the typical sample fat content from the literature. A detailed presentation of these calculations is given by Walstra et al. (1969) and Rüegg and Blanc (1981).

The laser Doppler electrophoresis apparatus and method for $\zeta$-potential analysis have been described in details by Michalski et al. (2002d). Measurements were performed with a ZetaSizer 3000HS (Malvern).

\section{Biochemical Analyses}

The fat content of mature milk samples was measured by the Gerber standard method (FIL, 1997).

\section{Statistical Analyses}

Size distribution parameters among different times PP, different breasts, or different milks were compared by using Student's $t$-test (Rice et al., 2000). Statistical significance was determined at $P<0.05$. The Systat program (SSI, Richmond, CA) was used. Trend curves for the evolution of fat globule diameter and SSA vs. time PP were obtained using the TableCurve 2D program (v. 4; SSI).

\section{RESULTS}

\section{Fat Globule Size Distribution of Colostrum and Transitional Milk}

Figure 2 shows the typical evolution of the MFG size distribution of 2 mothers during early lactation. Shortly after delivery, no fat globule $<1 \mu \mathrm{m}$ could be 


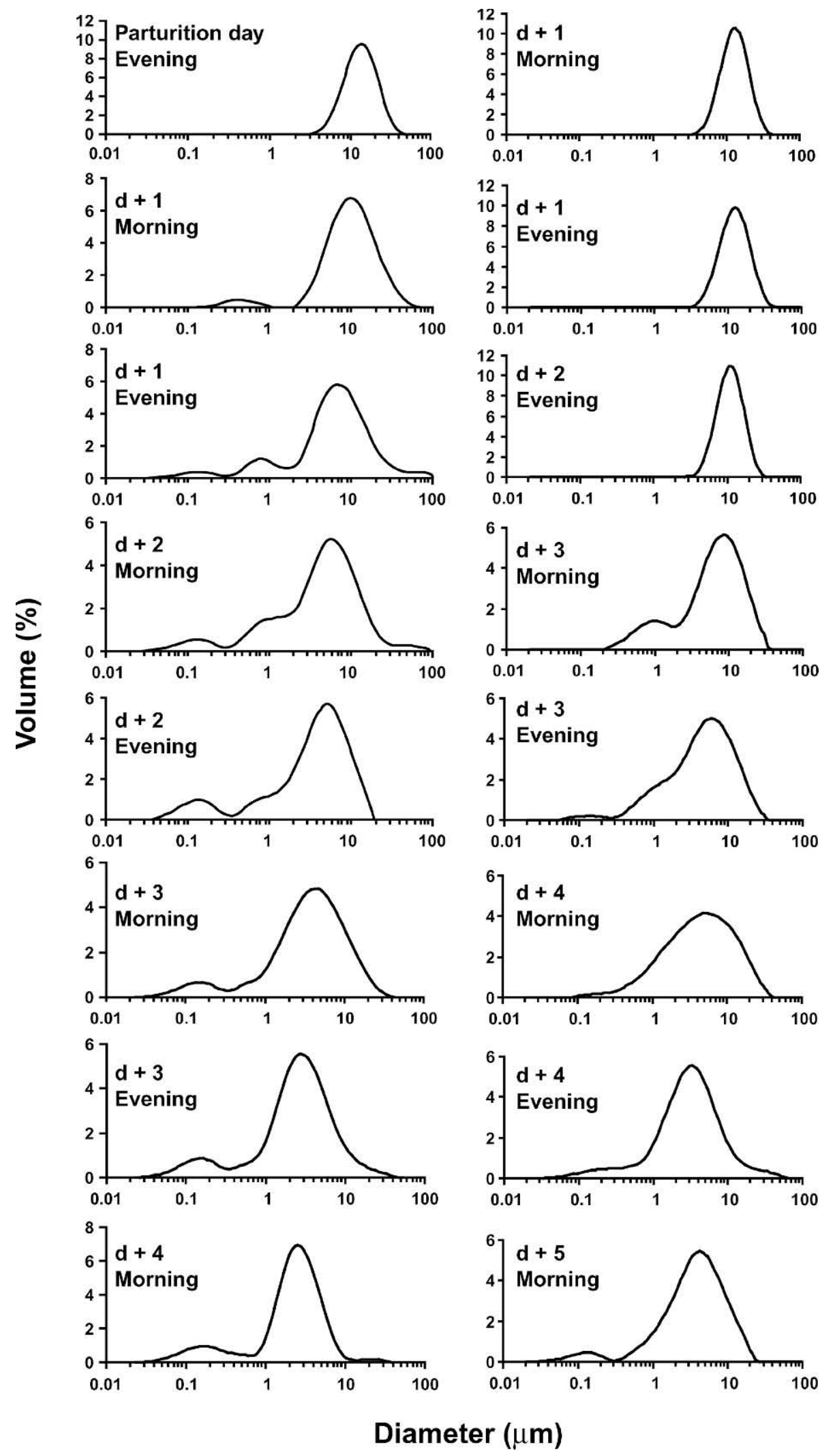

Figure 2. Examples of milk fat globule size distributions by volume (left column = mother \#13; right column = mother \#18) during the first lactation days. 

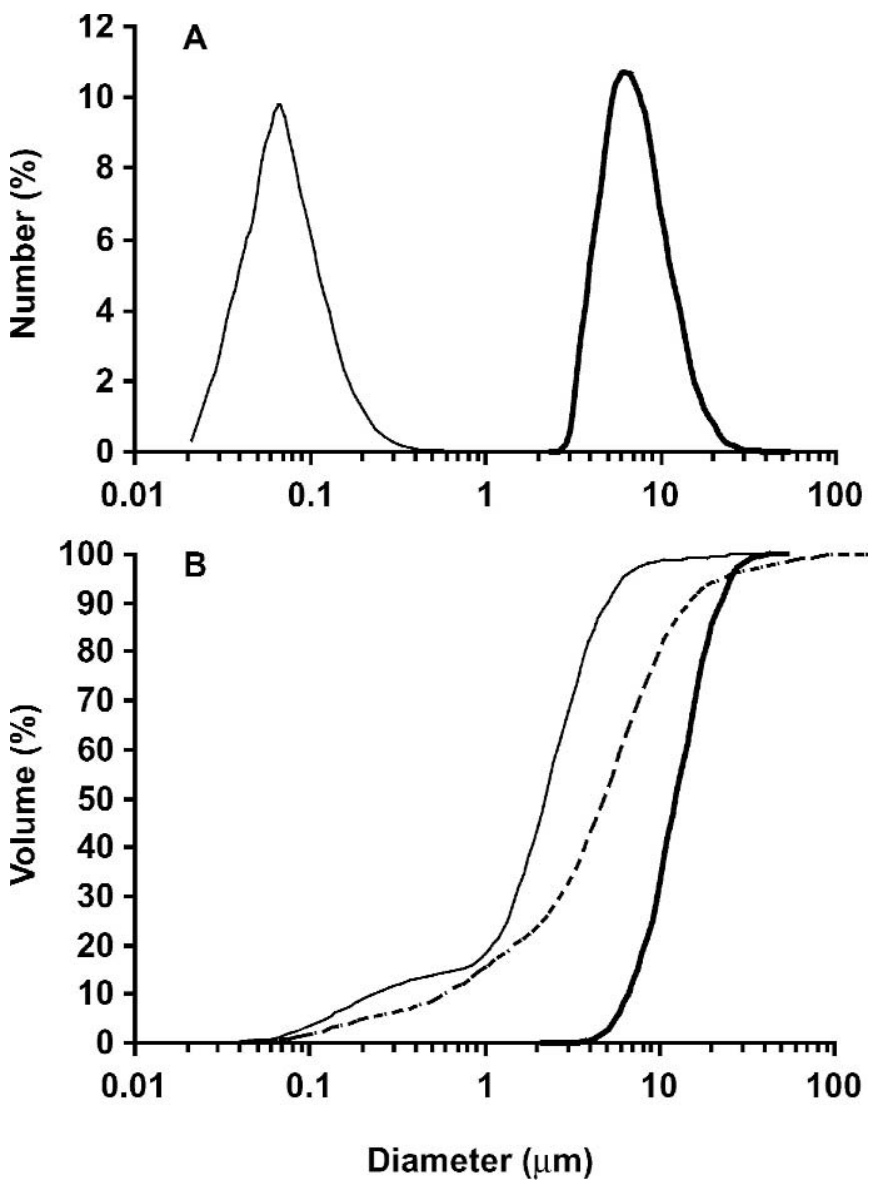

Figure 3. Milk fat globule size distribution (mother \#18). A) Distribution by number (thick line = delivery day evening; thin line $=$ fourth day morning). B) Cumulative distribution by volume (thick line = delivery day evening, dashed line = second day morning, and thin line $=$ fourth day morning).

observed. The mode diameter of the main fat globule population decreased with the lactation stage together with the appearance of populations of smaller MFG $<1 \mu \mathrm{m}$ with a mode diameter around $200 \mathrm{~nm}$.

We should highlight that the size distribution by volume, measured by laser light scattering, does not provide the same information as the size distributions by number, provided with a particle counter. Figure $3 \mathrm{~A}$ shows the number-transformed size distribution of MFG (calculated by the apparatus software) from mother \#18. Although most of the number of globules were $\geq 10 \mu \mathrm{m}$ on the evening of the delivery day, most of them were numerous and $<1 \mu \mathrm{m}$ on the fourth day, despite the $<20 \%$ representation of the total fat volume (Figure 3B). This is explained by the fact that 1 globule of $10-\mu \mathrm{m}$ diameter represents the same volume as $10^{3}$ globules of $1-\mu \mathrm{m}$ diameter, although being numerically in the minority. The increased volumic percentage of fat globules $<1 \mu \mathrm{m}$ during the first lactation days can be seen in Figure 3B.

\section{Diameters and SSA of Fat Globules in Colostrum and Transitional Milk}

Table 2 shows no significant difference of fat globule size parameters between milk expressed at the end of nursing on the sucked breast and milk expressed before nursing on the opposite breast. Additional experiments in our laboratory did not reveal any significant difference in MFG size during one nursing for mature milk (results not shown). On the whole, these findings are consistent with Whittlestone and Perrin (1954), who found no difference in fat globule size at the beginning and end of feeding for human milk by microscopic observations. No clear-cut explanation is available to date to explain this lack of difference.

Figure 4 shows some evolution curves of MFG mode, $\mathrm{d}_{43}$, SSA, and span as a function of the early lactation stage. (Seven typical examples were chosen for each size distribution parameter, representative of the different curve shapes observed in the study.) Mode and $\mathrm{d}_{43}$ both decreased with early lactation stage during the first $4 \mathrm{~d}$ in a nearly linear, exponential, or sigmoidal manner, depending on the mother. The SSA of MFG increased up to 9-fold from colostrum to transitional milk, as a result of the decrease of the particle size and increase of the volume fraction of globules $<1$ $\mu \mathrm{m}$ (Figure 3B). Most of the time, this increase was sigmoidal and could correspond to the onset of lactation. In most cases, the size distribution span increased from delivery to $4 \mathrm{~d} \mathrm{PP}$, although large discrepancies were observed among mothers.

One of the mothers (mother \#10) presented significantly larger MFG than the 17 other mothers, although her characteristics were in the average (31 yr old, $63 \mathrm{~kg}$ at delivery with 10-kg weight gain during pregnancy, third child, 8 previous mo of lactation, 39wk gestation time, delivery with epidural, no caesarean). Moreover, she gave fewer milk samples than other mothers. Therefore, the size distribution data corresponding to this mother were not taken into account further for means and statistical analyses.

Figure 5 shows the averaged mode, $\mathrm{d}_{43}$, and SSA of MFG as a function of the early lactation stage. Different trend curves were fitted to the weighted averaged data. Results were best fitted with a sigmoidal decrease of diameters and a sigmoidal increase of SSA. Average mode and SSA values at specific stages PP are reported in Table 3, together with the increase of SSA from early colostrum to 4-d milk. Average values before $48 \mathrm{~h} \mathrm{PP}$ were not significantly different, as well as after $60 \mathrm{~h}$ PP. However, the decrease of diameters 
Table 2. Comparison between mode, volumic average diameter $\left(\mathrm{d}_{43}\right)$, and specific surface area (SSA) of the fat globule population measured from milk extracted at the end of nursing from the sucked breast or from the opposite breast during the first $4 \mathrm{~d}$ postpartum (PP). Means are expressed \pm SEM. ${ }^{1}$

\begin{tabular}{|c|c|c|c|c|c|c|}
\hline \multirow[b]{2}{*}{ Time PP } & \multicolumn{2}{|c|}{ Mode } & \multicolumn{2}{|c|}{$d_{43}$} & \multicolumn{2}{|c|}{ SSA } \\
\hline & Sucked & Opposite & Sucked & Opposite & Sucked & Opposite \\
\hline & & - & & & $\longrightarrow$ & $\longrightarrow$ \\
\hline $15 \mathrm{~h}$ & $11.6 \pm 1.1$ & $8.8 \pm 1.7$ & - & - & - & - \\
\hline $50 \mathrm{~h}$ & $7.6 \pm 2.4$ & $7.8 \pm 1.2$ & $11.2 \pm 2.4$ & $13.3 \pm 0.0$ & $2.6 \pm 1.5$ & $1.6 \pm 0.0$ \\
\hline $75 \mathrm{~h}$ & $3.7 \pm 0.4$ & $3.7 \pm 0.4$ & - & - & - & - \\
\hline $80 \mathrm{~h}$ & $3.6 \pm 0.5$ & $3.2 \pm 1.1$ & $5.3 \pm 0.9$ & $5.9 \pm 2.0$ & $4.0 \pm 0.9$ & $6.4 \pm 1.9$ \\
\hline $90 \mathrm{~h}$ & $3.3 \pm 0.3$ & $2.5 \pm 0.1$ & $4.3 \pm 0.6$ & $3.9 \pm 0.6$ & $5.6 \pm 0.9$ & $4.6 \pm 1.7$ \\
\hline
\end{tabular}

${ }^{1} \mathrm{n}=3$ to 8 depending on time PP. $P>0.05$ between each sucked and opposite breast.

and increase of SSA were both significant between 48 and $72 \mathrm{~h} \mathrm{PP}$, which is consistent with the sigmoidal correlations observed previously (Figure 5). This difference should correspond to the average appearance of the transitional milk after colostrum.

\section{Fat Globule Size and $\zeta$-Potential in Mature Milk Throughout Lactation}

Figure 6A shows that the mode diameter of mature MFG from a single mother increased significantly from 3 to 20 mo lactation. Variations in diameter among milks extracted in the morning, midday, and evening were not found to be significant. The range of fat globule diameter for this mother is somewhat higher than reported in the literature (Rüegg and Blanc, 1981).

Plotting all together the diameter and SSA of mature MFG from different mothers at different stages of lactation (Figure 6B), the mode tended to increase, and SSA tended to decrease, between 2 and 12 mo of lactation. No differences were observed after 12 mo because of the smaller number of samples collected. In France, only $48.5 \%$ of mothers breastfeed after delivery, and only a few nurse $>3$ mo (Beaufrère et al., 2000).

The fat globule size was found to increase with mature milk fat content for one single mother who had given entire milk samples collected by mechanical expression (Figure 6C). This relationship between milk fat content and globule diameter is also known for cow milk (Wiking et al., 2004). This means that when milk fat content increases, the volume of fat globules increases rather than their number. This diameter dependency on fat content can also explain some of the observed variations of mode between morning and midday milk (Figure 6A) and the discrepancies between various mothers at the same stage of lactation (Figure 6B).

Figure 6A shows that the $\zeta$-potential of mature MFG did not increase significantly from 8 to 15 mo of lactation. The average $\zeta$-potential value was $-7.8 \pm 0.1 \mathrm{mV}$, the absolute value (negative surface charge) of which is lower than the mean value reported for cow MFG of $-13.5 \mathrm{mV}$ (Michalski et al., 2002d). The absolute value of $\zeta$-potential of human MFG was also lower than the value for homogenized milk fat droplets of $-20 \mathrm{mV}$ (Michalski et al., 2002d), such as for commercial MFG.

\section{Particle Size Distribution of Fat Droplets in Infant Formula}

Fat droplets in infant formula are not native MFG but homogenized ones, produced by emulsification of vegetable oils using a homogenizer. The resulting particles can be coated with phospholipids or proteins, depending on the formulation. Fat droplets in infant formula were much smaller than in human colostrum and milk (Table 4). The fat droplet size distribution from 2 different brands is presented in Figure 7. They were mainly constituted of submicronic droplets, which is consistent with previous studies on homogenized milk using the same measurement apparatus (Michalski et al., 2002c).

\section{DISCUSSION}

\section{Parameters of the Fat Globule Size Distribution in Different Milks}

The present results of human fat globule size within the first $48 \mathrm{~h}$ PP are new compared with the literature (Rüegg and Blanc, 1981). Our results regarding colostrum between 2 and $5 \mathrm{~d} \mathrm{PP}$ and average mature milk (Table 5) are consistent with those of Rüegg and Blanc (1981) and Simonin et al. (1984). Fat globule sizes presented in the literature as "initial" (Simonin et al., 1984) were smaller, and the SSA was larger than in our study. However, this difference is likely to be caused by the different early times PP between the 2 studies and the small number of initial samples in the study by Simonin et al. (1984). Moreover, some discrepancies 

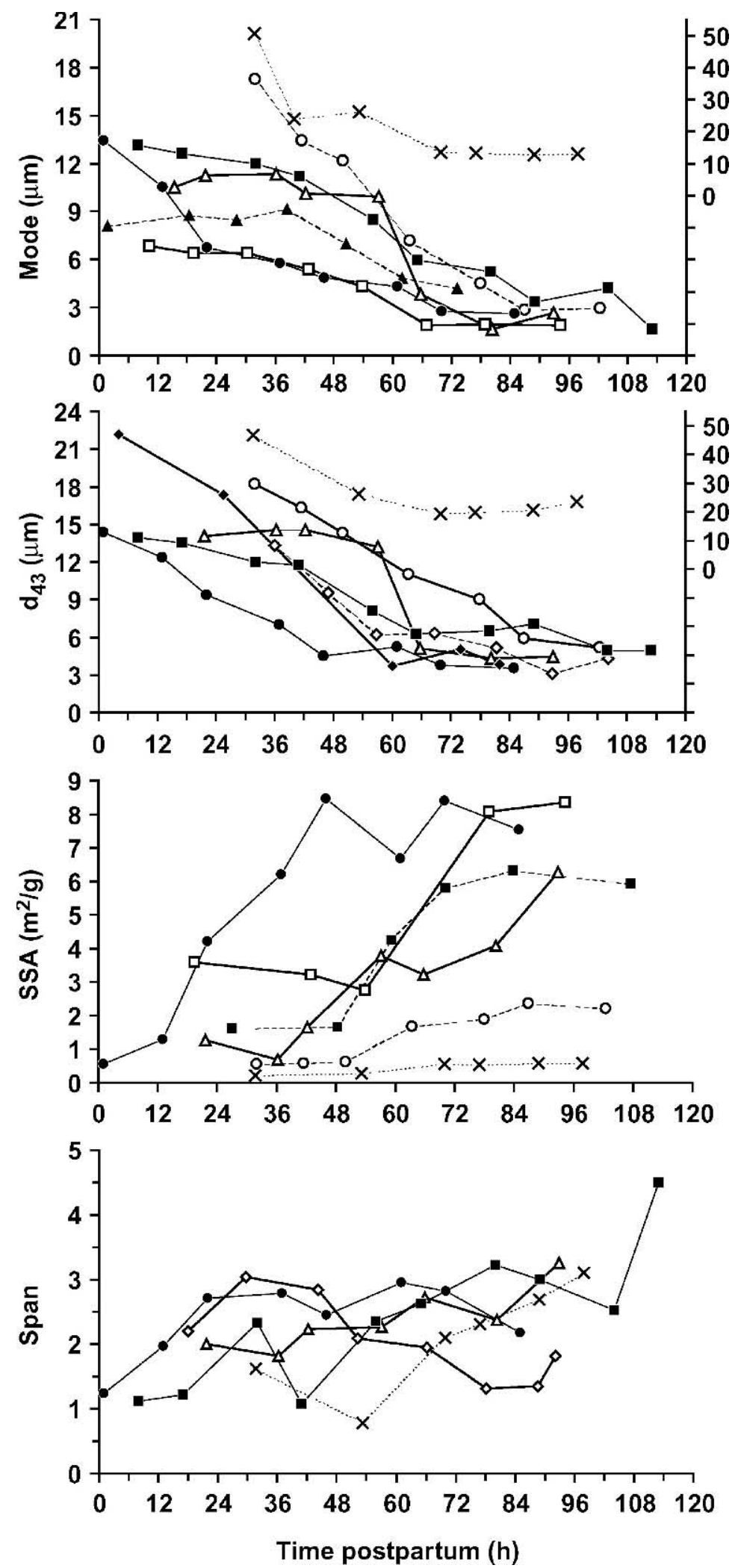

Figure 4. Mode diameter, volumic average diameter $\left(\mathrm{d}_{43}\right)$, specific surface area (SSA), and span of the milk fat globules of individual mothers during the first lactation days. Mother \#2 (----), mother \#3 (- $\Delta-)$, mother \#6 (.. $\diamond .$.$) , mother \#10 (..×..; on secondary axis), mother$

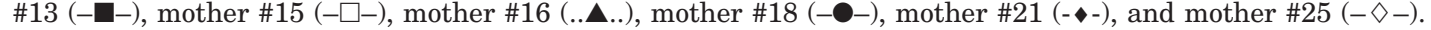


1934

MICHALSKI ET AL.
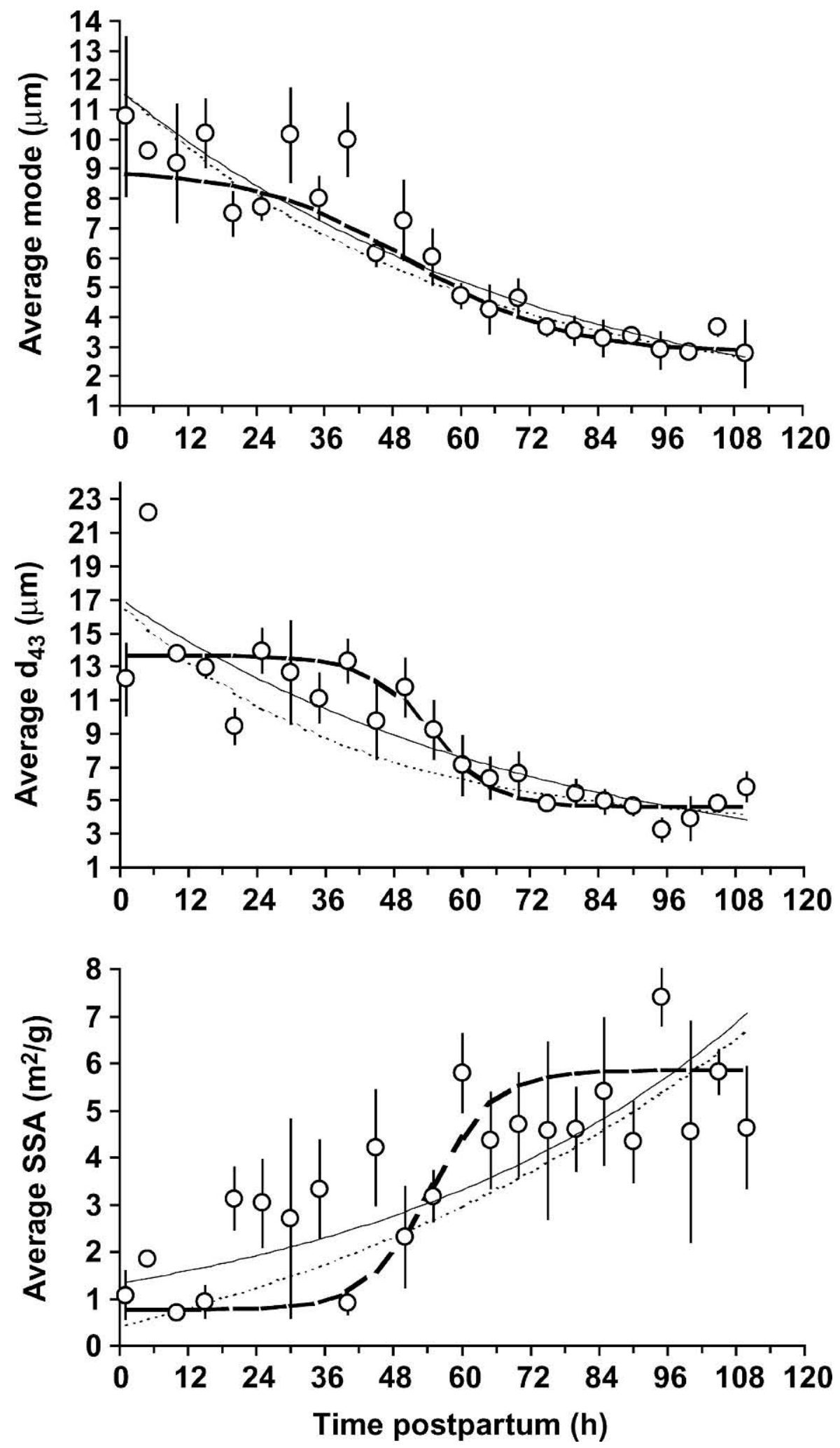

Figure 5. Average mode, average volumic average diameter $\left(\mathrm{d}_{43}\right)$, and average specific surface area (SSA) during the first lactation days calculated from the data of 17 mothers. Exponential trend curve $\left(y=a \times e^{-b \times x}\right)$ calculated with unweighted data: $R^{2}$ mode $=0.90, R^{2}{ }_{d 43}=$ $0.82 ; R^{2} \mathrm{~S}=0.60(-)$. Exponential trend curve $\left(\mathrm{y}=\mathrm{a}+\mathrm{b} \times \mathrm{e}^{-\mathrm{c} \times \mathrm{x}}\right)$ calculated with weighted data: $R^{2}{ }_{\text {mode }}=0.90, R^{2}{ }_{\mathrm{d} 43}=0.97 ; \mathrm{R}^{2} \mathrm{~S}=0.84$ $(--)$. Sigmoidal trend curve $\left[y=a+b \times\left(1+\mathrm{e}^{-(\mathrm{x}-\mathrm{c}) / \mathrm{d}}\right)^{-1}\right]$ calculated with weighted data: $R_{\text {mode }}^{2}=0.92, R^{2} 43=0.99 ; R^{2}=0.90(\mathbf{C})$.

Journal of Dairy Science Vol. 88, No. 6, 2005 
Table 3. Characteristic parameters of the milk fat globule population at various stages during the first 4 $\mathrm{d}$ postpartum $(\mathrm{PP})$. Mode = modal diameter of the main milk fat globule population; SSA = specific surface area; RI-S = relative increase of SSA; and I-S = increase of SSA. Means are expressed \pm SEM. ${ }^{1}$

\begin{tabular}{|c|c|c|c|c|}
\hline & $<12 \mathrm{~h} \mathrm{PP}^{1}$ & 36 to $48 \mathrm{~h} \mathrm{PP}$ & 60 to $72 \mathrm{~h} \mathrm{PP}$ & $>96 \mathrm{~h} \mathrm{PP}$ \\
\hline Mode, $\mu \mathrm{m}$ & $8.9^{\mathrm{a}} \pm 1.0$ & $7.7^{\mathrm{a}} \pm 0.7$ & $4.4^{\mathrm{b}} \pm 0.4$ & $2.8^{\mathrm{c}} \pm 0.3$ \\
\hline $\mathrm{SSA}, \mathrm{m}^{2} / \mathrm{g}$ & $1.1^{\mathrm{a}, 2} \pm 0.3$ & $2.6^{\mathrm{a}, 2} \pm 0.7$ & $4.5^{\mathrm{b}} \pm 0.7$ & $5.4^{\mathrm{b}} \pm 0.7$ \\
\hline $\begin{array}{l}\text { RI-S, \%/h } \\
\text { I-S } \mathrm{m}^{2} / \mathrm{g} \text { per }\end{array}$ & & $\begin{array}{r}4 \\
5.3 \cdot 10\end{array}$ & 8 & \\
\hline
\end{tabular}

${ }^{\mathrm{a}, \mathrm{b}}$ Values in a row with different superscripts are different $(P<0.02)$.

${ }^{1} \mathrm{n}=7$ to 16 depending on time PP.

${ }^{2} P=0.06$.

can be explained by the different techniques used to measure particle size distributions. In the studies by Rüegg and Blanc (1981), a particle counter was used, instead of a 2-laser light scattering apparatus in the present work. Therefore, raw data in the literature (Rüegg and Blanc, 1981) were obtained as size distributions by number, and the volumic distributions presented were obtained after mathematical transformation of the former. Moreover, Rüegg and Blanc (1981) suggested the predominance of the smallest fat globules $(<1 \mu \mathrm{m})$ in colostrum. However, it was not clear in their methods whether casein micelles were dissociated prior to particle counting. If not, because milk fat content is lower in early colostrum, some of the submicronic particles that were observed in their results might well be casein micelles. Finally, in the study of Rüegg and Blanc (1981), submicronic populations were estimated by extrapolation instead of being truly measured such as in our study.

In the present study, the appearance of subpopulations of different sized fat globules (Figure 3B) is consistent with Rüegg and Blanc (1981). However, in the latter reference, the number of small globules decreases significantly during the early stages of lactation. Using a finer measurement technique with dissociation of casein micelles and at earlier stages of lactation, we show a converse trend: the smallest MFG appear progressively from delivery to $4 \mathrm{~d} \mathrm{PP}$. Yet, our results agree with Rüegg and Blanc (1981) regarding the decrease in frequency of the largest particles during early stages of lactation. The higher amount of large fat globules in early colostrum can be accounted for if we assume that the immature mammary gland provides the fat droplets with incomplete membrane coating so that coalescence of small globules occurs (Simonin et al., 1984).

Averaging particle size results between 2 and $5 \mathrm{~d}$ PP (Table 5), we obtain larger average $d_{43}$ values than Rüegg and Blanc (1981). As mentioned previously, this could be due to the different techniques used. Moreover, this time range corresponded to the sigmoidal decrease that we highlight and that had never been shown before between $48 \mathrm{~h}\left(\mathrm{~d}_{43}=7.8 \pm 1.9 \mu \mathrm{m}\right)$ and $60 \mathrm{~h}\left(\mathrm{~d}_{43}=4.3 \pm 0.6 \mu \mathrm{m}\right)$. This final value is consistent with Rüegg and Blanc (1981) as well as size distribution parameters of mature human milk (Table 5). In short, we have shown that the human MFG size first decreased during the first $4 \mathrm{~d}$ of lactation, and that it subsequently increased in mature milk from the first month until the end of lactation.

The order of magnitude of human MFG diameter is similar to that of bovine MFG (Table 5). However, the diameter of mature human MFG increases with advancing lactation, conversely to bovine MFG (Mulder and Walstra, 1974; Rüegg and Blanc, 1981). Literature supports the theory that the secretory cells of the mammary gland are not able to increase the production of membrane material when the fat yield increases, which occurs with advancing lactation. Instead, the fat droplets have to grow larger before they are covered with plasma membrane in the secretory apical membrane (Wiking et al., 2004), which would explain the correlation between mature milk fat content and MFG size (Figure 6C). The release of lipid globules and the final size of the MFG may also be affected by hormones, such as prolactin and oxytocin (Ollivier-Bousquet, 2002). It is possible that the initial decrease in fat globule diameter during the first lactation days is due to the maturation of the mammary gland that progressively provides more and more membrane to cover MFG, while the subsequent increase in mature fat globule size during later months of lactation is due to the increased fat content and limited available membrane coverage. Moreover, in cow milk, fatty acid composition is linked to breed, feed, fat yield, and fat globule size (Briard et al., 2003; Mulder and Walstra, 1974; Wiking et al., 2004). It would be interesting to study the relationship between the fat content and fat globule size distribution of human milk and its fatty acid composition with mothers under a controlled diet. The effect of the duration of previous lactations on MFG size should also be studied. 

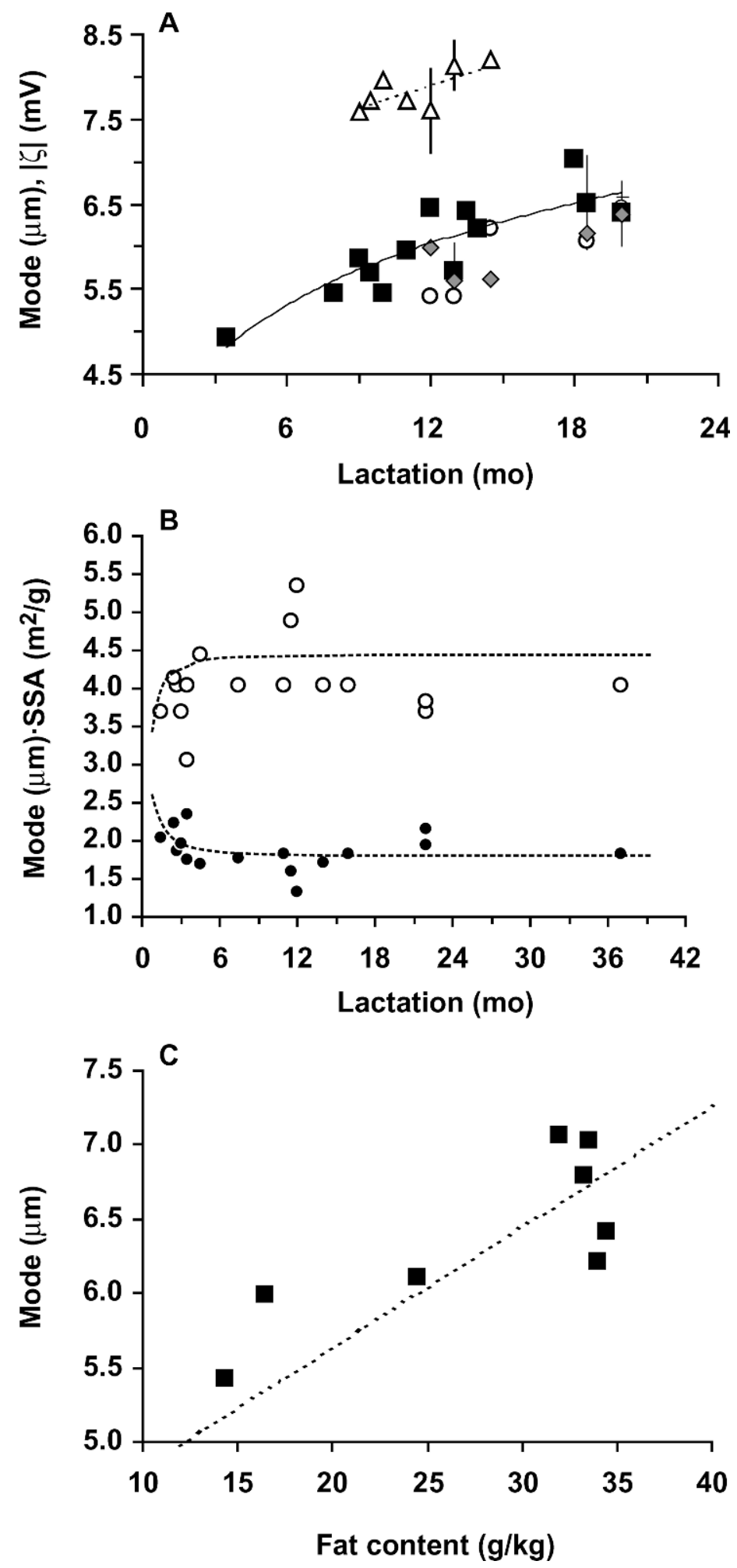

Figure 6. A) Mode diameter of mature milk fat globules ( $>3$ mo postpartum) of one single mother during lactation, from morning milk $(\bigcirc)$, midday milk $(\square)$, and evening milk $(\bullet)$ and $\zeta$-potential of mature milk fat globules from midday milk $(\Delta)$. Exponential trend curve $(\mathrm{y}=$ $\left.\mathrm{a} \times \mathrm{e}^{-\mathrm{b} \times \mathrm{x}}\right)$ for midday milk mode $\left(\mathrm{R}^{2}=0.77\right)$. B) Mode diameter $(O)$ and specific surface area (SSA; $\bullet$ ) of mature milk fat globules $(1.5$ to 37 mo postpartum) from 16 different mothers at various stages of lactation (lines are to guide the eye). C) Mode diameter of mature milk fat globules as a function of milk fat content measured from one single mother throughout lactation. 
Table 4. Average characteristic parameters $($ mode $=$ modal diameter of the main milk fat globule population, $\mathrm{d}_{43}=$ volumic average diameter, SSA = specific surface area, and span of the distribution) of the fat droplet size distribution in the 4 infant formulas tested. Means are expressed \pm SEM.

\begin{tabular}{lccr}
\hline & Minimum & Maximum & \multicolumn{1}{c}{ Mean } \\
\hline Mode, $\mu \mathrm{m}$ & 0.3 & 0.5 & $0.4 \pm 0.1$ \\
$\mathrm{~d}_{43}, \mu \mathrm{m}$ & 0.8 & 4.7 & $2.0 \pm 0.9$ \\
$\mathrm{SSA}, \mathrm{m}^{2} / \mathrm{g}$ & 18.2 & 26.2 & $22.1 \pm 1.7$ \\
Span & 2.7 & 17.3 & $7.6 \pm 3.3$ \\
\hline
\end{tabular}

Regarding infant formula (Table 5), we obtained smaller diameters and larger SSA than Simonin et al. (1984). This result can be explained by the different measuring techniques, the different formula-making processes, and the new homogenization techniques that have appeared since 1984 (Pouliot et al., 1990). Particularly, the size distribution measurement method employed by Simonin et al. (1984) prevented them from accurately characterizing particles $<1 \mu \mathrm{m}$ that are obviously in the majority in infant formula. Our results, however, are consistent with the diameter range found in homogenized cow milk (Table 5). The discrepancy could also be due to different formula composition, assuming that some formulas studied by Simonin et al. (1984) might have contained some lactic fat, including cholesterol and phospholipids, possibly affecting emulsification and final fat droplet size.

\section{Possible Link Between Fat Interface Properties in Different Milks and its Digestibility}

Compartmentation is one of the factors (with enzyme activity and state of the intestinal absorptive

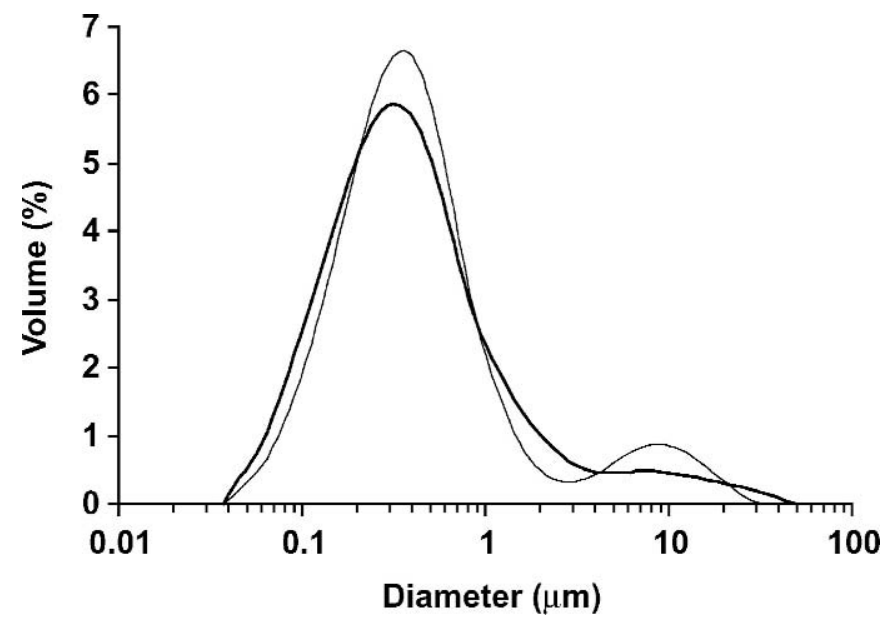

Figure 7. Examples of fat droplet size distributions of infant formulas. Thick line $=$ Gallia $1^{\text {er }}$ âge, Danone; thin line $=$ Guigoz $2^{\mathrm{e}}$ âge, Nestlé.

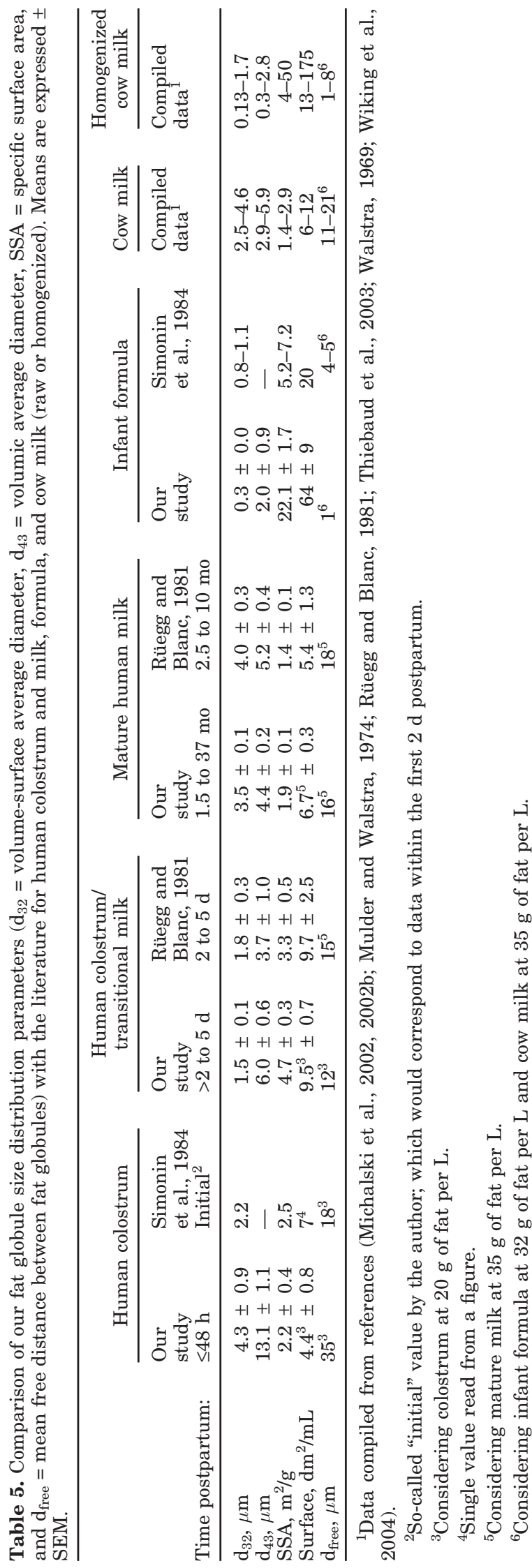

Journal of Dairy Science Vol. 88, No. 6, 2005 
surface) that controls the flow of nutrients into the enterocyte when milk has been consumed. A review of milk compartments is presented by Jensen et al. (1990), one of the most important being the MFG and their interface where lipolytic activity occurs. Also, the presence of bile-salt stimulated lipase in human milk aids in the digestion of lipids in newborns because of its unique wide substrate specificity (Lönnerdal, 2003). The interfacial structure and the available fat surface area in milk are, thus, of primary importance for adequate lipolysis and digestion.

To our knowledge, the $\zeta$-potential of human MFG had never been measured previously. Glycoproteinaceous filaments have been observed at the surface of human MFG, but not bovine ones (Jensen et al., 1990). Moreover, the human MFG membrane contains more sphingomyelin. These differences can contribute to their different $\zeta$-potential and can have consequences on the adsorption of lipases onto the human MFG surface.

Regarding the available fat surface area for lipolysis, because the average milk fat content in the first $2 \mathrm{wk}$ of lactation is reported to increase from 15 to 20 $\mathrm{g} / \mathrm{L}$ to 30 to $40 \mathrm{~g} / \mathrm{L}$ (Rüegg and Blanc, 1981; Marangoni et al., 2002), our results mean that the total milk fat surface area in colostrum should lie from 1.8 to 2.2 $\mathrm{dm}^{2} / \mathrm{mL}$ and could increase after $4 \mathrm{~d}$ of lactation up to 9 to $11 \mathrm{dm}^{2} / \mathrm{mL}$ (at 16 to $20 \mathrm{~g} / \mathrm{L}$ ) or even 16 to $22 \mathrm{dm}^{2} /$ $\mathrm{mL}$ (at 30 to $40 \mathrm{~g} / \mathrm{L}$ ). The latter values are consistent with the literature (Table 5). Therefore, the increase in fat content (according to the literature) and increase in SSA from colostrum to transitional milk results in a 5 to 10 -fold increase in surface area of fat per unit volume of milk. In mature milk, the average milk fat content lies in the range of 21 to $48 \mathrm{~g} / \mathrm{L}$ (Villalpando and del Prado, 1999), and, from Figure 6B, the SSA was in the range of 1.3 to $2.3 \mathrm{~m}^{2} / \mathrm{g}$, so that we can estimate a surface area of MFG between 3 and $11 \mathrm{dm}^{2}$ / $\mathrm{mL}$ (Table 5; consistent with the literature). In infant formula, the fat content is in the range of 24 to $34 \mathrm{~g} / \mathrm{L}$ according to the manufacturers. Therefore, the surface area of fat in infant formulas was in the range of 50 to $89 \mathrm{dm}^{2} / \mathrm{mL}$, which is significantly higher than in human colostrum and milk (Table 5). Consequently, formula-fed newborns receive products with a fat interface up to 50 times greater than in human colostrum in their first $48 \mathrm{~h}$, up to 6 times greater after $4 \mathrm{~d}$, and up to 28 times greater in later months. We should highlight that the fat surface values presented in Table 5 for human colostrum and milk are an average for one feed. Because, during one feed, the lipid proportion increases 3-fold (Simonin et al., 1984), the surface is smaller than this average at the beginning of nursing and larger at the end.
In rats and human adults, large native fat globules result in fast gastric emptying and metabolization; small homogenized lipid particles result in a slower gastric emptying and delayed metabolization (Borel et al., 1994; Armand et al., 1999; Michalski et al., 2005). In the infant, however, results are conflicting. Armand et al. (1996) found no effect of the type of diet on the rate of stomach emptying; Cavell (1981) found a slower gastric emptying rate with infant formula. This discrepancy could be due to a difference of fat droplet interface composition, as droplets coated with caseins are likely to remain entrapped within the gastric coagulum (Michalski et al., 2002a), which would delay their gastric emptying. However, droplets coated with phospholipids would not interact with caseins and could drain easier. Armand et al. (1996) observed a more efficient gastric digestion of the fat in human milk (greater gastric lipolysis, lower fat excretion, higher fat absorption), which they suppose is related to the structure and size of the fat particles in human milk compared with formula. This is all the more possible, as their electron microscopy observations revealed that the fat particles maintain their original shape at the end of gastric digestion (Armand et al., 1996). It has been shown, however, that homogenization of pasteurized human milk improved fat absorption in very low birth weight infants (Pimenteira Thomaz et al., 1999).

\section{CONCLUSIONS}

Regarding the present new results about the larger fat globule size of colostrum in the first $2 \mathrm{~d} P \mathrm{PP}$, it should be studied whether this could be an adaptation to the immature digestive system of the neonate and participate in an efficient and rapid digestion of colostrum lipids. The impact of much smaller-sized fat droplets on the lipid digestion metabolism in formula-fed newborns during the first days should be more exhaustively studied. As suggested by Armand (1998) and considering our new $\zeta$-potential results, we should stress that, in addition to the particle size distribution, the supramolecular structure of human MFG may be a key point of their functional properties for the newborn.

\section{ACKNOWLEDGMENTS}

The volunteer mothers are gratefully acknowledged for providing breast milk samples. We are indebted to the midwives and nurses of the Hospital of Rennes for informing the volunteer mothers and for helping collect the colostrum and milk samples. The authors thank E. Beaucher for milk composition analyses. A. 
Lacerte is acknowledged for editing the English language of the manuscript.

\section{REFERENCES}

Aksit, S., N. Ozkayin, and S. Caglayan. 2002. Effect of sucking characteristics on breast milk creamatocrit. Paediatr. Perinat. Epidemiol. 16:355-360.

Anderson, M., and T. E. Cawston. 1975. Reviews of the progress of dairy science. The milk fat globule membrane. J. Dairy Res. 42:459-483.

Armand, M. 1998. Propriétés physico-chimiques des émulsions lipidiques: Effets sur la digestion et l'assimilation des lipides. Cah. Nutr. Diet. 33:305-311.

Armand, M., M. Hamosh, N. R. Mehta, P. A. Angelus, J. R. Philpott, T. R. Henderson, N. K. Dwyer, D. Lairon, and P. Hamosh. 1996. Effect of human milk or formula on gastric function and fat digestion in the premature infant. Pediatr. Res. 40:429-437.

Armand, M., B. Pasquier, M. André, P. Borel, M. Senft, J. Peyrot, J. Salducci, H. Portugal, V. Jaussan, and D. Lairon. 1999. Digestion and absorption of 2 fat emulsions with different droplet sizes in the human digestive tract. Am. J. Clin. Nutr. 70:1096-1106.

Beaufrère, B., J. L. Bresson, A. Briend, J. Ghisolfi, O. Goulet, J. Navarro, G. Putet, C. Ricour, D. Rieu, D. Turck, and M. Vidailhet. 2000. La promotion de l'allaitement maternel: C'est aussi l'affaire des pédiatres. Arch. Pediatr. 7:1149-1153.

Bitman, J., D. L. Wood, M. Hamosh, and P. Hamosh. 1983. Comparison of the lipid composition of breast milk from mothers of term and preterm infants. Am. J. Clin. Nutr. 38:300-312.

Borel, P., M. Armand, B. Pasquier, M. Senft, G. Dutot, C. Melin, H. Lafont, and D. Lairon. 1994. Digestion and absorption of tube-feeding emulsions with different droplet sizes and compositions in the rat. J. Parenter. Enteral Nutr. 18:534-543.

Briard, V., N. Leconte, F. Michel, and M. C. Michalski. 2003. The fatty acid composition of small and large naturally occuring milk fat globules. Eur. J. Lipid Sci. Technol. 105:677-682.

Cavell, B. 1981. Gastric emptying in infants fed human milk or infant formula. Acta Paediatr. Scand. 70:639-641.

Christie, W. W. 1995. The composition and structure of milk lipids. Pages 1-36 in Advanced Dairy Chemistry. 2. Lipids, 2 ed. P. F. Fox, ed. Chapman \& Hall, London, UK.

Emmett, P. M., and I. S. Rogers. 1997. Properties of human milk and their relationship with maternal nutrition. Early Hum. Dev. 49(Suppl.):7-28.

Fidler, N., and B. Koletzko. 2000. The fatty acid composition of human colostrum. Eur. J. Nutr. 39:31-37.

FIL. 1997. Lait et produits laitiers, détermination de la teneur en matière grasse, standard 152A. Int. Dairy Fed., Brussels, Belgium

Francois, C. A., S. L. Connor, L. C. Bolewicz, and W. E. Connor. 2003. Supplementing lactating women with flaxseed oil does not increase docosahexaenoic acid in their milk. Am. J. Clin. Nutr. 77:226-233.

Francois, C. A., S. L. Connor, R. C. Wander, and W. E. Connor. 1998. Acute effects of dietary fatty acids on the fatty acids of human milk. Am. J. Clin. Nutr. 67:301-308.

Hamosh, M., J. Bitman, D. L. Wood, P. Hamosh, and N. R. Mehta. 1985. Lipids in milk and the first steps in their digestion. Pediatrics 75 (Suppl.): $146-150$.

Hamosh, M., J. A. Peterson, T. R. Henderson, C. D. Scallan, R. Kiwan, R. L. Ceriani, M. Armand, N. R. Mehta, and P. Hamosh. 1999. Protective function of human milk: The milk fat globule. Semin. Perinat. 23:242-249.

Jensen, R. G., A. M. Ferris, C. J. Lammi-Keefe, and R. A. Henderson. 1990. Lipids of bovine and human milks: A comparison. J. Dairy Sci. 73:223-240.

Keenan, T. W. 2001. Milk lipid globules and their surrounding membrane: A brief history and perspectives for future research. J. Mammary Gland Biol. Neoplasia 6:365-371.

Keenan, T. W., and D. P. Dylewski. 1995. Intracellular origin of milk lipid globules and the nature and structure of the milk lipid globule membrane. Pages 89-130 in Advanced Dairy Chemistry Vol. 2: Lipids, 2 ed. P. F. Fox, ed. Chapman \& Hall, London, UK.

Lönnerdal, B. 2003. Nutritional and physiologic significance of human milk proteins. Am. J. Clin. Nutr. 77(Suppl.):1543S-1553S.

Lopez, C., P. Lesieur, G. Keller, and M. Ollivon. 2000. Thermal and structural behavior of milk fat. 1. Unstable species of cream. J. Colloid Interface Sci. 229:62-71.

Lucas, A., J. B. Gibbs, and J. D. Baum. 1977. What's in breast milk? Lancet ii:1011.

Marangoni, F., C. Agostoni, A. M. Lammardo, M. Bonvissuto, M. Giovannini, C. Galli, and E. Riva. 2002. Polyunsaturated fatty acids in maternal plasma and in breast milk. Prostaglandins Leukot. Essent. Fatty Acids 66:535-540.

McCrae, C. H., and A. Lepoetre. 1996. Characterization of dairy emulsions by forward lobe laser light scattering-Application to milk and cream. Int. Dairy J. 6:247-256.

McPherson, A. V., and B. J. Kitchen. 1983. Reviews of the progress of dairy science: The bovine milk fat globule membrane-its formation, composition, structure and behaviour in milk and dairy products. J. Dairy Res. 50:107-133.

Michalski, M. C., V. Briard, M. Desage, and A. Géloën. 2005. The dispersion state of milk fat influences triglyceride digestibility in the rat: $\mathrm{A}^{13} \mathrm{CO}_{2}$ breath test study. Eur. J. Nutr. Available online (DOI: 10.1007/s00394-005-0551-1).

Michalski, M. C., V. Briard, and F. Michel. 2001. Optical parameters of milk fat globules for laser light scattering measurements. Lait 81:787-796.

Michalski, M. C., R. Cariou, F. Michel, and C. Garnier. 2002a. Native vs damaged milk fat globules: Membrane properties affect the viscoelasticity of milk gels. J. Dairy Sci. 85:2451-2461.

Michalski, M. C., F. Michel, and V. Briard. 2002b. On the size distribution and zeta-potential of homogenized milk fat globules. Pages 49-65 in Food Emulsions and Dispersions. M. Anton, ed. Research Signpost, Kerala, India.

Michalski, M. C., F. Michel, and C. Geneste. 2002c. Appearance of submicronic particles in the milk fat globule size distribution upon mechanical treatments. Lait 82:193-208.

Michalski, M. C., F. Michel, D. Sainmont, and V. Briard. 2002d. Apparent zeta-potential as a tool to assess mechanical damages to the milk fat globule membrane. Colloids Surfaces B 23:23-30.

Mulder, H., and P. Walstra. 1974. The Milk Fat Globule. Emulsion Science as Applied to Milk Products and Comparable Foods. Commonwealth Agricultural Bureaux, Farnham Royal, Bucks, UK.

Ollivier-Bousquet, M. 2002. Milk lipid and protein traffic in mammary epithelial cells: Joint and independant pathways. Reprod. Nutr. Develop. 42:149-162.

Pimenteira Thomaz, A. C., A. Lopes Gonzalves, and F. Eulogio Martinez. 1999. Effect of human milk homogenization on fat absorption in very low birth weight infants. Nutr. Res. 19:483-492.

Pouliot, Y., M. Britten, and B. Latreille. 1990. Effect of high-pressure homogenization on a sterilized infant formula: Microstructure and age gelation. Food Struct. 9:1-8.

Rice, A. L., R. J. Stoltzfus, A. de Francisco, and C. L. Kjolhede. 2000. Evaluation of serum retinol, the modified-relative-dose-response ratio, and breast-milk vitamin $\mathrm{A}$ as indicators of response to postpartum maternal vitamin A supplementation. Am. J. Clin. Nutr. 71:799-806.

Rüegg, M., and B. Blanc. 1981. The fat globule size distribution in human milk. Biochem. Biophys. Acta 66:7-14.

Rüegg, M., and B. Blanc. 1982. The particulate constituents of human milk. A review. Food Microstruct. 1:25-47.

Schweigert, F. J., K. Bathe, F. Chen, U. Büscher, and J. W. Dudenhausen. 2004. Effect of the stage of lactation in humans on caroteinoid levels in milk, blood plasma and plasma lipoprotein fractions. Eur. J. Nutr. 43:39-44.

Simonin, C., M. Rüegg, and D. Sidiropoulos. 1984. Comparison of the fat content and fat globule size distribution of breast milk from mothers delivering term and preterm. Am. J. Clin. Nutr. 40:820-826.

Thiebaud, M., E. Dumay, L. Picart, J. P. Guiraud, and J. C. Cheftel. 2003. High pressure homogenization of raw bovine milk. Effects 
on fat globule size distribution and microbial inactivation. Int. Dairy J. 13:427-439.

Villalpando, S., and M. del Prado. 1999. Interrelation among dietary energy and fat intakes, maternal body fatness, and milk total lipid in humans. J. Mammary Gland Biol. Neoplasia 4:285-295.

Walstra, P. 1969. Studies on milk fat dispersion. II. The globulesize distribution of cow's milk. Neth. Milk Dairy J. 23:99-110.

Walstra, P. 1995. Physical chemistry of milk fat globules. Pages 131-178 in Advanced Dairy Chemistry Vol. 2: Lipids, 2 ed. P. F. Fox, ed. Chapman \& Hall, London, UK.
Walstra, P., H. Oortwijn, and J. J. de Graaf. 1969. Studies on milk fat dispersion. I. Methods for detemining globule size distribution. Neth. Milk Dairy J. 23:13-36.

Whittlestone, W. G., and D. R. Perrin. 1954. Variations in the fat content of human milk during suckling. J. Dairy Res. 21:204206.

Wiking, L., J. Stagsted, L. Björck, and J. H. Nielsen. 2004. Milk fat globule size is affected by fat production in dairy cows. Int. Dairy J. 14:909-913. 